\title{
Análise de Custos e do Impacto Ambiental no Descarte de Resíduos Sólidos
}

Pós-Graduação em Gestão de Custos pela Centro Universitário parg Desenvolvimento do Alto Vale do Itajaí - UNIDAVI Economista na Universidade Regional de Blumenau - FURB Rua Dr. Guilherme Gemballa, 13. Jardim América. Rio do Sul/SC. CEP: 89160-932 E-mail: r.creutzberg@outlook.com

Mara Juliana Ferrari Doutorado em Contabilidade pela Universidade Federal de Santa Catarina - UFSC Professora no Centro Comunitário para Desenvolvimento do Alto Vale do Itajaí UNIDAVI

Rua Dr. Guilherme Gemballa, 13. Jardim América. Rio do Sul/SC. CEP: 89160-932 E-mail:mara@unidavi.edu.br

Emanuele Engelage Doutorado em andamento em Contabilidade pela Universidade Federal de Santa Catarina - UFSC R. Servidão Oscar Raul da Silva, 271. Trindade. Florianópolis/SC. CEP: 88036-645 E-mail: manuengelage@hotmail.com

\section{RESUMO}

As práticas ambientais têm se intensificado devido à crescente conscientização em relação à limitação de disponibilidades, à falta de locais para disposição final de resíduos e à importância da manutenção dos recursos naturais. Dessa forma e, ao se considerar a crescente imposição legislativa, como a Política Nacional dos Resíduos Sólidos, as empresas buscam se adequar às prerrogativas de sustentabilidade, a fim de aliar fatores econômicos aos socioambientais e melhorar sua imagem. Este estudo consiste em verificar a viabilidade, com base nos custos de tratamento e na análise de efeitos ambientais, da utilização de um picador que reduz a cubagem de resíduos sólidos produzidos por uma empresa multinacional do ramo metal-mecânico localizada no Vale do Itajaí. Para tanto, analisa-se a variação nos custos de transporte, tratamento e armazenagem desses resíduos, ao se comparar o cenário atual com um alternativo, onde, antes do envio ao aterro sanitário, realiza-se a picotagem. Os dados revelam que, quando há necessidade de contratação de pessoal para a função de picotagem, seja integralmente ou proporcional às horas requeridas, a alteração incorre em desvantagem financeira, com elevação proporcionalmente maior dos gastos totais. Entretanto, se houver a alocação de pessoal interno, a empresa obtém vantagens financeiras. Sob o aspecto ambiental, a redução da cubagem de resíduos resulta em benefícios, ao elevar o tempo de vida útil do aterro sanitário, em função da redução de área ocupada e do tempo de decomposição dos materiais. 
Palavras-chave: Viabilidade Financeira. Desenvolvimento sustentável. Resíduos sólidos.

\title{
Analysis of Costs and Environmental Impact in the discard of Solid Waste
}

\begin{abstract}
The environmental practices have intensified due the growing awareness in relation of availability limitation, the lack of places for final disposal of waste and the importance of maintaining natural resources. In this way, and considering the growing legislative imposition, such as the National Solid Waste Policy, the companies seek to adapt to the prerogatives of sustainability, in order to ally economic to the socio-environmental factors and improve their image. This study consists to verifying the viability, based on the treatment costs and the analysis of environmental effects, in the utilization of a waste grinder that reduces the solid waste cubage produced by a multinational company of metal mechanical line located in the Vale do Itajaí region. Therefore, it is analyzed the variation in transportation, treatment and storage costs of these waste, when comparing the current scenario with an alternative, where, before the shipment to the sanitary landfill, it is realized the waste grinding. The data reveal that, when there is a need of hiring staff for the waste grinding function, either in totally or in proportion to the required hours, the alteration incurs is financially disadvantageous, with an elevation proportionately higher in total costs. However, if there is internal staff allocation, the company gets financial advantage. From the environmental aspect, the reduction of the cubing waste results in benefits, by increasing the useful life of the landfill, due to the reduction of the occupied area and the decomposition time of the materials.
\end{abstract}

Keywords: Financial viability. Sustainable development. Solid Waste.

\section{INTRODUÇÃO}

As preocupações com questões ambientais têm se intensificado nos últimos anos devido à crescente conscientização em relação à limitação de disponibilidades e à importância dos recursos naturais para manutenção da vida na Terra. Segundo Ribeiro e Santos (2013), esta conscientização se dá, principalmente, em função dos impactos gerados pelas ações humanas no ambiente e de suas consequências, como o aquecimento global e a exploração dos recursos naturais finitos.

Dessa forma e, ao se considerar que esses impactos são causados principalmente pelas atividades desenvolvidas ao longo da cadeia de suprimentos, há 
uma crescente preocupação e cobrança para que as empresas se adequem às prerrogativas de sustentabilidade, afim de aliar fatores econômicos aos socioambientais. Problemas de desempenho ambiental podem afetar a imagem e as negociações de uma empresa. Para evitar esses percalços, busca-se a interação de programas de sustentabilidade e práticas proativas que potencializem o uso de recursos, diminuam a poluição e agreguem valor à empresa (Rogers \& Tibben-Lembke, 1999; Ribeiro \& Santos, 2013).

Outro fator que condiciona as empresas a atuarem de forma ambientalmente correta é a crescente imposição legislativa. No Brasil, a Lei n. 12.305 (2010) instituiu a Política Nacional de Resíduos Sólidos (PNRS), a qual define diretrizes e objetivos, com vistas a incentivar práticas de consumo sustentável na busca pela prevenção e redução na geração de resíduos. A PNRS é considerada por Marchese, Konrad e Calderan (2011), um marco regulatório no país, e sua relevância intensifica-se ao considerar as estimativas de que o volume de resíduos produzido pela sociedade cresce mais do que a própria população mundial e seu descarte inadequado pode provocar sérias e danosas consequências à saúde pública e ao meio ambiente (Ministério do Meio Ambiente, 2016a).

Dentre as políticas estabelecidas por esta normatização, pode-se citar o aumento da reciclagem, da reutilização de resíduos e da destinação adequada dos rejeitos. A referida Lei também institui a responsabilidade compartilhada dos geradores de resíduos, estabelece instrumentos de planejamento, cria metas, dentre as quais destaca-se a eliminação dos lixões, e impõe que os particulares, ou seja, empresas, órgãos responsáveis e municípios elaborem seus Planos de Gerenciamento de Resíduos Sólidos (Lei n. 12.305, 2010).

Entretanto, segundo Rogers e Tibben-Lembke (1999), a introdução de práticas sustentáveis, seja motivada pela legislação, pela conscientização ambiental ou pela cobrança do mercado, pode acarretar acréscimos de custos às organizações, o que intensifica a necessidade de seu gerenciamento. Planejar e controlar os custos decorrentes de práticas sustentáveis, ao se optar por metodologias e procedimentos 
que visem à integração entre características ambientais, econômicas e sociais pode representar um diferencial competitivo às organizações, com vistas à continuidade de suas operações (Rogers \& Tibben-Lembke, 1999).

Nesse sentido, torna-se relevante analisar os impactos, tanto ambientais como financeiros, decorrentes do tratamento adequado de resíduos sólidos, a fim de identificar como medidas socioambientais contribuem para atenuar os efeitos causados ao ambiente. Para tanto, o presente estudo direciona-se a uma empresa do segmento de metal-mecânico, localizada no Vale do Itajaí - Santa Catarina (SC), haja vista que, dentre os resíduos existentes em sua atividade, encontram-se materiais que necessitam de tratamento específico em sua destinação.

Dentre as medidas de tratamento adequado de resíduos sólidos, ou seja, atividades de armazenagem, transporte e manuseio com enfoque socioambiental, podem-se considerar diversas formas e ferramentas, pois há ligação direta com o tipo do resíduo, suas especificações e riscos inerentes. No caso da empresa em análise, uma das possibilidades é a redução de cubagem do material destinado aos aterros sanitários, por meio da picotagem realizada por equipamento específico.

Diante deste contexto, este estudo estabelece a seguinte questão de pesquisa: Qual a viabilidade, com base nos custos de tratamento e na análise de efeitos ambientais, da utilização de um picador que reduz a cubagem de resíduos sólidos destinados ao aterro sanitário na empresa analisada?

Ao analisar o impacto nos custos de tratamento (armazenamento, manuseio e transporte dos resíduos) e os efeitos causados ao ambiente, por meio da análise do tempo de decomposição dos materiais e espaço ocupado no aterro sanitário, este estudo verifica a viabilidade de utilização de um picador adquirido pela empresa em dezembro de 2011. Isso porque a eventual alteração nos processos atuais de tratamento desses resíduos, por meio da redução de seu volume em metros cúbicos, é condicionada pelos gestores à viabilidade financeira e ambiental.

Dessa forma, este estudo visa contribuir com a empresa, ao servir de base para a tomada de decisão no que concerne ao tratamento desses resíduos. Também busca- 
se incentivar outras organizações, mesmo que de segmentos distintos, a considerarem quesitos socioambientais e não meramente financeiros e econômicos em seus processos decisórios, visto que propicia maior compreensão de impactos financeiros e ambientais decorrentes da adequação sustentável em um processo específico e a reflexão sobre suas potencialidades e pontos a serem aperfeiçoados.

Além da contribuição prática, este estudo visa contribuir, também, para a consolidação literária acerca do tema, ao trazer maiores esclarecimentos sobre a relação de critérios financeiros e ambientais. Autores como Rogers e Tibben-Lembke (1999) alegam que condutas ecológicas representam acréscimos de custos às organizações, mas deve-se ponderar que uma gestão eficiente pode potencializar o uso dos recursos, diminuir custos de obsolescência e deterioração, dinamizar as atividades, incorporar tecnologias e valorizar sua imagem (lakovou, Mallidis, Vlachos \& Dekker, 2014).

\section{REFERENCIAL TEÓRICO}

Com o crescimento industrial, as empresas têm aumentado gradativamente a sua produção. Em decorrência disso, retiram-se da natureza grandes quantidades dos mais diversos recursos naturais, bem como geram-se resíduos em maior quantidade, visto que esses referem-se aos restos de matérias-primas e outros produtos que fazem parte do processo produtivo (Silva \& Cervieri, 2015).

Segundo a Associação Brasileira de Normas Técnicas - ABNT (2004), os resíduos sólidos industriais são todos os resíduos no estado sólido ou semissólido resultantes das atividades industriais, que incluem lodos e determinados líquidos, cujas características tornam inviável seu lançamento na rede pública de esgotos ou corpos d'água, ou que exijam para isso soluções, técnica e economicamente, inviáveis.

O gerenciamento inadequado de tais resíduos pode resultar em riscos indesejáveis à sociedade, como problemas de saúde pública e a degradação ambiental, além dos aspectos sociais, estéticos, econômicos e administrativos envolvidos 
(Secretaria do Meio Ambiente do Estado de São Paulo, 2014). Em função disso, há algumas décadas se discute, em âmbito nacional e internacional, sobre as preocupações com a destinação e o reaproveitamento de resíduos sólidos (Ministério do Meio Ambiente, 2016b).

A complexidade e interação entre as demandas ambientais, sociais e econômicas denota a necessidade de um reposicionamento quanto às atitudes sustentáveis por parte de empresas, governos e sociedade. Neste sentido, em 2010, foi aprovada no Brasil a Política Nacional de Resíduos Sólidos (PNRS), por meio da Lei 12.305/10, que se tornou uma fonte de articulação institucional na busca por soluções dos problemas de gestão de resíduos. Essas políticas envolvem tanto os entes federativos (União, Estado e Municípios), como o setor produtivo e a sociedade como um todo (Ministério do Meio Ambiente, 2016b).

"A Lei sancionada incorpora conceitos modernos de gestão de resíduos sólidos e se dispõe a trazer novas ferramentas à legislação ambiental brasileira" (Ministério do Meio Ambiente, 2016a), como, por exemplo: institui a responsabilidade compartilhada pelo ciclo de vida dos produtos; estabelece acordos setoriais; incentiva práticas de logística reversa e coleta seletiva; cria regras para o ciclo de vida de alguns produtos; fortalece a classe de catadores de lixo, dando-lhe mais incentivos; obriga os particulares a criarem seus planos de resíduos sólidos; e cria o sistema de informações sobre a gestão dos resíduos sólidos (Ministério do Meio Ambiente, 2016a).

Diante da pressão legislativa pelo comprometimento das organizações na destinação correta de rejeitos e pelo reaproveitamento de resíduos, torna-se importante conhecer suas especificidades e possibilidades de adequação, uma vez que há meios específicos de tratamento para cada tipo de resíduo.

Segundo a norma ABNT NBR 10.004, de 2004, os resíduos sólidos industriais são classificados da seguinte forma: (a) Resíduos de Classe I - Perigosos - que, em função de suas propriedades físico-químicas e infectocontagiosas como inflamabilidade, corrosividade, reatividade, toxicidade e patogenicidade, podem apresentar risco à saúde pública e ao meio ambiente; (b) Resíduos de Classe II (a) - 
Não Inertes - são aqueles que não se enquadram nas classes I ou II (b) e apresentam propriedades específicas, tais como: combustibilidade, biodegrabilidade ou solubilidade em água: (c) Resíduos de Classe II (b) - Inertes - são resíduos que, submetidos a um contato estático ou dinâmico com água, não têm nenhum de seus componentes solubilizados a concentrações superiores aos padrões de potabilidade de água definidos pelo Anexo H da Norma NBR 10.004 (Compromisso Empresarial para Reciclagem - Cempre, 2016).

A compreensão quanto às características e propriedades de cada resíduo tornase fator relevante para determinar a forma e os atributos de sua destinação final, uma vez que é comum realizar tratamentos com vistas à sua reutilização ou, ao menos, à sua inertização. Dada a diversidade desses resíduos, não existe um processo de tratamento pré-estabelecido e há a necessidade de análises prévias para identificar ações financeiramente viáveis e ecologicamente corretas (ABNT, 2004).

Uma das possibilidades para essa destinação são os aterros sanitários, que são locais utilizados para o depósito final de resíduos sólidos gerados pela atividade humana. Neles são dispostos resíduos domésticos, comerciais, de serviços de saúde, da indústria de construção e, também, resíduos sólidos retirados do esgoto (Brasil \& Santos, 2010). A vida útil de um aterro varia de acordo com a quantidade de lixo que nele é depositado, com duração média de 20 a 25 anos (Silva \& Cervieri, 2015).

Os aterros sanitários são locais com preparo para receber os resíduos, onde se realiza o controle das substâncias contaminantes por meio da impermeabilização do solo, que impede o vazamento de chorume e possibilita a captação do gás metano, liberado pela decomposição de matérias orgânicas e cujo aproveitamento se dá pela transformação em energia (Brasil \& Santos, 2010).

Diferentemente dos aterros sanitários, nos lixões, que também são locais para depósito final de resíduos, não há qualquer tipo de tratamento; portanto, tornam-se fontes de poluição (Brasil \& Santos, 2010). Entretanto, conforme já mencionado, a PNRS traça como uma de suas metas a eliminação de lixões, com vistas a propiciar uma destinação adequada aos rejeitos e, dentro do possível, reaproveitar os resíduos 
antes de sua destinação final. Quando este reaproveitamento não é possível, os aterros sanitários são a opção mais recomendada, devido às suas características de preservação e cuidado com o ambiente.

Silva e Cervieri (2015) reforçam a ideia de que os aterros sanitários são o melhor meio para a destinação de rejeitos que não podem ser reaproveitados. Os autores realizaram um estudo para demonstrar os problemas causados pelo lixo e a necessidade de realizar a destinação correta, dentro dos padrões e normas. Apesar de avaliarem diferentes alternativas de destinação, a principal conclusão do estudo é que a redução do impacto ambiental está condicionada, primeiramente, à redução da quantidade de lixo produzido. Para os autores, a população está consumindo mais do que necessita e, se comparado com o crescimento populacional, a tendência para o futuro é uma situação caótica.

Brollo e Silva (2001) afirmam que, na década 1970, deu-se uma importância maior para a recuperação e reciclagem dos materiais. Entretanto, atualmente, a tendência é estabelecer políticas que levem à prevenção e redução do volume dos resíduos gerados desde o início do processo produtivo, o que condiz com as afirmações de Silva e Cervieri (2015). Para tanto, o gerenciamento de resíduos sólidos vem passando por um processo de reformulação, com vistas à diminuição na fonte, por meio da minimização do consumo de energia, do desperdício de materiais e, consequentemente, do impacto ambiental (Brollo \& Silva, 2001). Entretanto, mesmo quando há diminuição do consumo, a geração de resíduos é inerente à atividade produtiva e, portanto, o reaproveitamento e a destinação ambientalmente correta são fatores importantes para que se atinja o patamar de sustentabilidade desejado.

Luczkievicz, Menegat e Figueiredo (2015) apresentam uma abordagem geral sobre a destinação de resíduos sólidos das indústrias do ramo metal-mecânico localizadas no município de Chapecó-SC. O estudo envolve um mapeamento de informações das empresas, como: porte; tipos de resíduos produzidos; existência de políticas de destinação ambientalmente amigáveis; conhecimento sobre legislação ambiental vigente; e dados sobre custos de desenvolvimento e manutenção de 
sistemas para destinação adequada de resíduos. Os achados indicam que $100 \%$ das empresas analisadas contam com terceiros para a disponibilização dos resíduos em aterros sanitários controlados e legalizados, a fim de evitar multas e complicações ambientais. Luczkievicz et al. (2015) alegam ainda que essa destinação adequada elimina a possibilidade de contaminações do solo, corpos hídricos e ar, além do surgimento de vetores causadores de doenças infecciosas.

Henry, Yongsheng e Jun (2006) realizaram um estudo para avaliar a gestão de resíduos sólidos urbanos no Quênia. Para os autores, fatores como o fraco crescimento econômico, o aumento do nível de pobreza e a evasão das áreas rurais para as urbanas, além de aumentar o volume dos resíduos produzidos, também contribuem para que a sua destinação ocorra de forma não planejada e inadequada. Em decorrência disso, há um aumento da poluição das águas superficiais e subterrâneas em função do despejo ilegal nas margens de rios ou na beira de estradas. Além do mais, há falta de infraestrutura e financiamentos para incentivar e proporcionar condições para uma destinação correta.

Diante do exposto, percebe-se que, seja relacionado à redução na geração de resíduos ou à sua eliminação, o conceito de logística reversa é intrínseco. Segundo Ciliberti, Pontrandolfo e Scozzi (2008), a logística reversa refere-se ao processo de reciclagem, reutilização, triagem, reuso e eliminação correta de produtos e materiais usados, a fim de reduzir desperdícios e aumentar o desempenho organizacional.

Marchese et al. (2011) realizaram uma pesquisa que busca contextualizar a logística reversa e a educação ambiental como fatores que contribuem para a aplicabilidade da PNRS. Os autores tomam por base empresas de países da Europa que já demandam a gestão de resíduos sólidos com resultados positivos há mais de uma década, a fim de analisar como a logística reversa é implantada nessas empresas e identificar semelhanças e diferenças em relação ao Brasil, no intuito de apresentar recomendações. Para os autores, o Brasil ainda está muito aquém dos países europeus no que tange ao engajamento do poder público, da sociedade civil, dos profissionais 
envolvidos, consumidores e titulares de serviços, na busca pelo aprimoramento entre todos os atores sociais.

Mesmo com essas limitações, o que se pode perceber é que há uma tendência de elevação no que tange à conscientização na destinação ambientalmente correta dos resíduos sólidos. Todavia, torna-se também necessário conhecer os impactos financeiros dessas práticas, para que se possa obter um desenvolvimento sustentável, ou seja, agregar fatores econômicos e socioambientais. Porém, conforme demonstrado nos estudos supracitados, muitas análises direcionam-se para a gestão de resíduos e seu impacto ambiental, sem considerar questões financeiras. Em contrapartida, há estudos que realizam análises de custos, mas com enfoque em ações de reutilização e aproveitamento de materiais e não no descarte final de resíduos, conforme proposto nesta análise (Daher, Silva, \& Fonseca, 2006; Souza \& Fonseca, 2009).

Diferentemente, Kuzma, da Luz, Novak e Navarro (2017) possuem este direcionamento ao analisarem os custos de tratamento e de destinação dos resíduos sólidos e efluentes gerados pelas atividades de postos de revenda de combustíveis. Os autores consideram custos de tratamento aqueles relacionados ao armazenamento, movimentação e destinação de resíduos, dentre os quais destacam: valor de recolhimento do barro; custos do armazenamento e mão de obra para a armazenagem; e custo do descarte, que inclui transporte e eliminação. Dentre os principais achados, Kuzma et al. (2017) destacam o fato de as empresas analisadas limitarem-se a cumprir as obrigações legais para o manejo dos resíduos e de os custos representarem uma parcela média/pequena do lucro bruto. Diante disso, os autores afirmam que é possível e viável pequenas empresas adotarem práticas conscientes de gestão ambiental, haja vista que a variação na representatividade de custos por adotarem essas condutas não é tão significativa e podem, paralelamente, evitar multas e melhorar sua imagem.

Cabe destacar que, segundo Claro e Claro (2014), os benefícios financeiros de uma prática socioambiental podem ser resultado de economia nos custos ou no incremento de receitas. Além disso, segundo os autores, há benefícios estratégicos que resultam da melhor imagem institucional, do aumento da produtividade $e$ 
potencialização no uso de recursos, do alto comprometimento do pessoal e da melhora das relações com os órgãos governamentais, comunidade e grupos ambientalistas. Portanto, torna-se necessário conhecer as possibilidades para descarte de resíduos sólidos e, assim, verificar os benefícios financeiros e ambientais de cada alternativa, a fim de contribuir para uma tomada de decisão mais assertiva e consciente.

\section{METODOLOGIA}

A fim de possibilitar o alcance do objetivo proposto, do ponto de vista metodológico, este estudo caracteriza-se, quanto aos procedimentos, como um estudo de caso. Segundo Gil (2002), este tipo de pesquisa busca maior aprofundamento do assunto, ao compreender, explorar ou descrever acontecimentos em um contexto específico. Dessa forma, busca-se verificar as alterações nos custos e no impacto ambiental, ao se adotar um procedimento diferenciado no descarte de resíduos sólidos em uma empresa multinacional do ramo metal-mecânico, localizada no Vale do Itajaí, em Santa Catarina.

Os dados utilizados referem-se às informações de custos de tratamento, quantidade produzida e dados operacionais específicos, como quantidades de materiais consumidos e de resíduos gerados. Também se analisa o funcionamento dos procedimentos internos que envolvem a geração e destinação desses resíduos. Para esta pesquisa, consideram-se custos de tratamento aqueles relacionados ao armazenamento, manuseio e transporte dos resíduos, como, por exemplo: mão de obra, energia elétrica e taxa de destinação ao aterro. As análises direcionam-se exclusivamente aos custos que sofrem alterações com a possível mudança dos processos, ou seja, custos adicionais ou que são reduzidos pela utilização do picador. Um exemplo de custo que permanece inalterado e, portanto, não é descrito nas análises, é a depreciação. Isso porque o equipamento foi adquirido pela empresa em 2011 e a depreciação já é considerada nos registros contábeis pelo método linear. 
Dessa forma, o valor depreciado independe do uso do maquinário para picotar os resíduos, uma vez que este é subutilizado em relação à sua capacidade real.

Para analisar o impacto ambiental, considera-se o espaço ocupado no aterro sanitário, que já atende as especificidades legais, bem como o tempo de decomposição dos resíduos. Demais características ambientais e dos agentes poluidores não são consideradas, pois o potencial poluidor dos materiais que compõem os resíduos permanece inalterado, independentemente de haver ou não a redução de seu volume, sendo que, conforme já mencionado, esse estudo tem como enfoque as alterações entre as condições atuais e posteriores ao processo de picotagem.

As informações são coletadas por meio de pesquisa documental nos relatórios contábeis e gerenciais e entrevistas não estruturadas junto aos responsáveis pela empresa dos departamentos de custos e de produção. Também se realizam entrevistas junto aos dirigentes da empresa que recebe os resíduos para tratamento, ou seja, o aterro sanitário, com a intenção de obter informações técnicas como o tempo de vida médio do aterro e de decomposição dos resíduos. Realizam-se observações diretas, a fim de visualizar e compreender os procedimentos internos da empresa e fornecer base informacional para as análises realizadas. Após coletados, os dados são exportados para o software Microsoft Excel®, onde são tabulados e analisados.

Salienta-se que o estudo toma por base os anos de 2013 a 2015, nos quais os resíduos gerados na empresa foram destinados ao aterro sanitário da forma como saem do processo produtivo, sem qualquer tratamento. Paralelamente, cria-se também um cenário alternativo, para verificar a viabilidade financeira e ambiental da utilização de um picador, que reduz o volume, em metros cúbicos, dos resíduos gerados pela empresa, antes da destinação ao aterro sanitário. Por fim, comparam-se os resultados obtidos (situação atual $X$ utilização do picador), a fim de verificar a viabilidade financeira de alterar 0 processo de destinação dos resíduos. Também se analisam comparativamente alguns impactos ambientais causados, em função do tempo de decomposição e utilização de espaço físico (em m³). 


\section{RESULTADOS E DISCUSSÕES}

A empresa objeto de análise localiza-se no Vale do Itajaí, no estado de Santa Catarina, e tem como atividade principal a produção de peças para a linha automotiva, destinada ao mercado nacional e à exportação para a América Latina e a Europa. Produz, em média, 20 toneladas de resíduos sólidos por mês, sendo que esse total inclui materiais como: papelão hidráulico, restos de metais, sobras de borrachas, papel, plásticos, pallets de madeira, entre outros materiais de consumo e limpeza. A Figura 1 apresenta o fluxograma do processo de geração de resíduos na empresa.

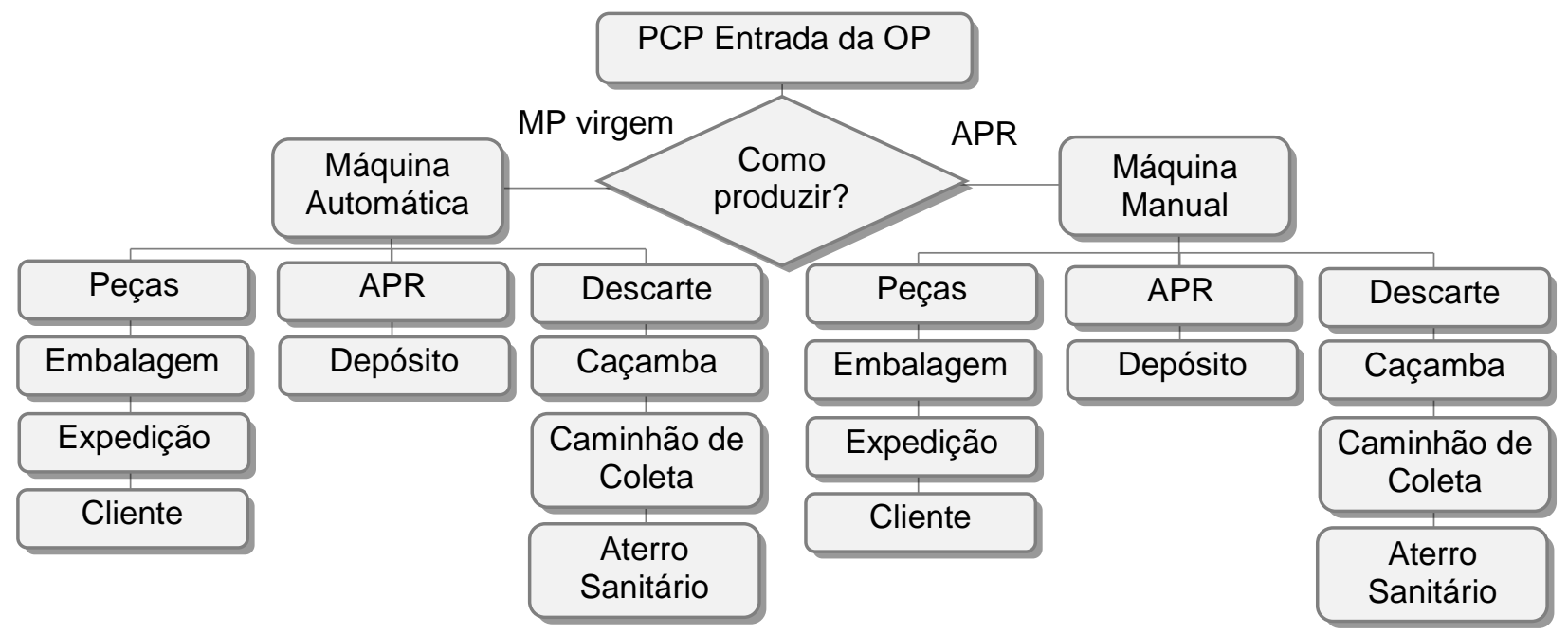

Figura 1. Fluxograma do processo na geração de resíduos sólidos.

Fonte: Elaborada pelos autores com base nos dados de pesquisa.

O Fluxograma da Figura 1 mostra, desde o início, o processo produtivo na fabricação de uma peça na empresa. No recebimento de uma Ordem de Produção (OP), é definido pelo Planejamento e Controle de Produção (PCP) como o processo ocorrerá, em que se levam em consideração vários fatores como: quantidade de peças a serem produzidas, ocupação das máquinas, gargalo, prazo de entrega e - o principal o estoque da matéria-prima, seja ela virgem ou do Aproveitamento (APR). Quando se utiliza matéria-prima (MP) virgem, a peça é produzida por uma máquina automática que 
resulta, nesse exemplo, em três itens distintos: (i) a peça que se deseja; (ii) partes que podem ser reaproveitadas na produção de outras peças menores (APR); e (iii) os resíduos que são descartados. As partes reaproveitáveis ficam estocadas, e quando o PCP requer seu consumo, utiliza-se a máquina manual, que é alimentada peça por peça. Após, seguem-se os mesmos procedimentos do fluxo original com a matériaprima virgem.

O aproveitamento da matéria-prima que sobra no processo inicial para produzir peças menores visa reduzir o consumo de materiais na fonte, o que vai ao encontro da proposta de Brollo e Silva (2001) e Silva e Cervieri (2015). A separação da peça produzida, do material que será descartado e do possível material que pode ser reaproveitado (APR) é demonstrada na Figura 2. Neste exemplo, a máquina automática produz, em uma única batida, diferentes peças, bem como apresenta sobras de materiais que podem ser aproveitados ou considerados como resíduos.

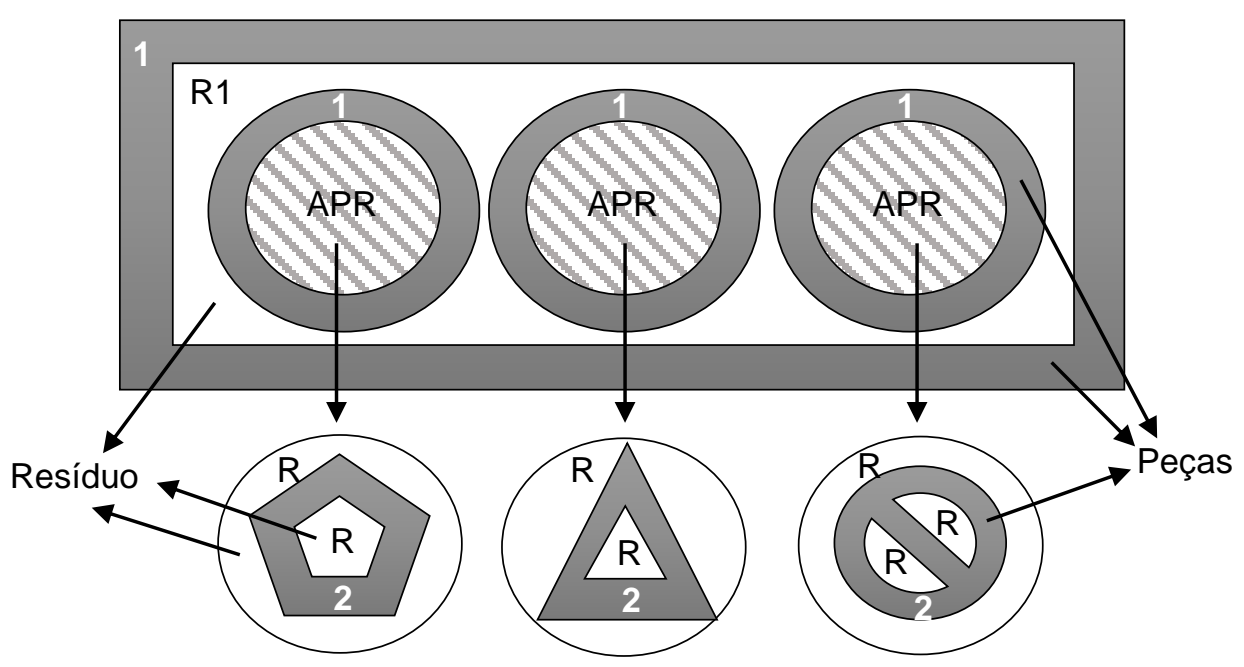

Figura 2. Peças e resíduos sólidos gerados

Fonte: Elaborada pelos autores com base nos dados de pesquisa.

A parte sólida de cor cinza escuro, retratada na Figura 2 pelo número um (1), refere-se às peças produzidas com matéria-prima virgem em uma máquina automática, 
provenientes de uma OP que dá entrada no PCP. Neste primeiro momento, é produzida, em uma única batida da máquina, uma peça retangular grande e três peças redondas menores. Após o término da $\mathrm{OP}$, as peças seguem seu fluxo e vão para os setores de embalagem, expedição e, posteriormente, para o cliente, conforme retratado no fluxograma do processo (Figura 1). Ainda na Figura 2, as peças com preenchimento em listras cinzas são consideradas aproveitamento (APR), ou seja, matéria-prima que pode ser reaproveitada na produção de peças menores. Esses pedaços vão para um depósito, no aguardo de uma nova OP. A parte branca da figura, representada pela sigla (R1), é considerada resíduo e, portanto, será depositada em uma caixa metálica ao lado da máquina e, posteriormente, descartada.

Completando o fluxo do processo de produção de resíduos (Figura 1) e, ao se considerar a entrada de uma nova OP no PCP, analisam-se as possibilidades para direcionamento do processo produtivo, ou seja, se requisita uma nova chapa de material virgem, retomando o processo detalhado anteriormente, ou se há possibilidade de aproveitamento das peças decorrentes de outros processos produtivos.

No caso de aproveitamento das sobras que estão no depósito, utiliza-se a máquina manual. Este processo resulta em três peças de diferentes medidas e aplicações, que são representadas na Figura 2 pela cor cinza escuro e marcadas pelo número (2). Após a conclusão da $\mathrm{OP}$, as peças também seguem seu fluxo normal (embalagem, expedição e cliente) e as sobras, de cor branca, marcadas pela sigla $(R)$, agora são consideradas como resíduos e descartadas.

Todos os resíduos gerados na produção são depositados em caixas metálicas identificadas por cores distintas. Os processos supracitados geram resíduos de papelão hidráulico que não têm alto potencial de poluição ao meio ambiente e, portanto, são depositados em uma caixa de cor verde (Resíduos de Classe II (a) - Não Inertes). Estas caixas posicionam-se ao lado de cada máquina para facilitar seu descarte e, quando estão cheias, são transportadas com uma empilhadeira até a parte externa da empresa, em local coberto, onde os materiais são depositados em uma caçamba maior. Esta caçamba é de propriedade da empresa coletora dos resíduos e tem capacidade de 
receber, em média, 5 toneladas de resíduos, o que equivale a $25 \mathrm{~m}^{3}$ de material. Semanalmente, esta caçamba é transportada para o aterro sanitário localizado na cidade de Chapecó - SC.

No decorrer do processo produtivo, também há caixas metálicas de cor vermelha onde são depositados os resíduos de Classe I, considerados perigosos, pois têm alto potencial de contaminação do meio ambiente. Esses materiais referem-se às latas de tintas, estopas sujas com graxas, óleos, restos de borrachas, entre outros e, assim como os demais resíduos, são posteriormente depositados em uma caçamba separada de menor tamanho, na parte externa da empresa e em local coberto, e também são destinados para o aterro sanitário.

\subsection{Volumes e Valores dos Resíduos Sólidos no Processo Atual}

A empresa, durante vários anos, tem investido em caixas metálicas para a separação dos resíduos sólidos no decorrer do processo produtivo, pois esses materiais possuem destinação diferenciada de acordo com suas especificações. Mensalmente, são produzidos, em média, $90 \%$ de resíduos de classe II (a) e 10\% de classe I. Os papeis, caixas de papelão e metais são vendidos como sucatas; os pallets de madeira são doados; já o papelão hidráulico, que é a matéria-prima mais usada (classe II a), as latas de tinta, borracha, estopas sujas com óleo e graxa (classe I) são destinados ao aterro sanitário.

Ao considerar todos os materiais que vão para o aterro sanitário, mensalmente são destinados, em média, 20 toneladas de resíduos sólidos industriais da empresa para o aterro localizado na cidade de Chapecó - SC. Na Tabela 1, apresenta-se o resumo das toneladas e gastos mensais e anuais, correspondentes ao envio desses resíduos. 
Análise de Custos e do Impacto Ambiental no descarte de Resíduos Sólidos

Ralf Creutzberg, Mara Juliana Ferrari, Emanuele Engelage

Tabela 1

Resumo de toneladas e valores (mensais e anuais) da destinação de resíduos

\begin{tabular}{ccccc}
\hline Ano & Ton. Ano & Ton. Mês & Valor (R\$) Ano & Valor (R\$) médio mês \\
\hline 2013 & 260,96 & 21,75 & $52.909,90$ & $4.409,16$ \\
2014 & 259,78 & 21,65 & $53.253,30$ & $4.437,78$ \\
2015 & 234,6 & 19,55 & $49.266,00$ & $4.105,50$ \\
Média & 251,78 & 20,98 & $51.809,73$ & $4.317,48$ \\
\hline
\end{tabular}

Nota. Fonte: Elaborada pelos autores com base nos dados de pesquisa.

$\mathrm{Na}$ Tabela 1, são descritos os dados para destinação dos resíduos nos três anos analisados, incluindo o valor médio, em toneladas e em moeda corrente, quais sejam: 20,98 toneladas mensais a um custo médio de $R \$ 4.317,48 / \mathrm{mês}$. Assim há, em média, 20 toneladas ao mês e um adicional de 980 quilogramas, o que gera, ao longo do ano, aproximadamente duas cargas adicionais. No intuito de apresentar o comparativo mensal entre os cenários, o custo dessas duas cargas é rateado igualmente ao longo dos doze meses, independentemente de quando ocorram. Portanto, o gasto médio para destinação desses resíduos até o aterro sanitário é de $R \$ 4.199,00$ mensais, sendo assim distribuídos:

- 4,20 cargas/mês (251,78 toneladas/ano e, aproximadamente, cinco toneladas por carga). O valor de cada carga é $R \$ 500,00$, o que totaliza um gasto com frete de $R \$$ $2.100,00$ mensais.

- O gasto com destinação do resíduo é de $R \$ 100,00$ a tonelada. Este é o valor pago para a empresa terceirizada para depositar os resíduos no aterro. Ao considerar que, ao ano, são depositadas 251,78 toneladas $(R \$ 25.178,00)$, o custo médio mensal é de $R \$ 2.099,00$.

Os gastos com a movimentação de resíduos pela empilhadeira dentro da empresa não são contabilizados separadamente $e$, consequentemente, não são apropriados a esta atividade. Isso porque, estes valores são considerados irrisórios, uma vez que este fluxo não é frequente e é realizado por pessoal não específico, ou 
seja, que realizam outras funções na empresa e que, conforme disponibilidade, conduzem as caixas de resíduos até a caçamba externa.

\subsection{Utilização do Picador no Descarte dos Resíduos Sólidos}

A empresa adquiriu, em dezembro de 2011, um picador, ou seja, um equipamento para trituração dos materiais. Na época, tinha intenção de triturá-lo para descarte, pois, dessa forma, estimava-se que se poderia dobrar a capacidade em volume/peso na caçamba. Entretanto, até o momento, esta mudança não foi colocada em prática.

Atualmente, a capacidade de transporte por carga é de $25 \mathrm{~m}^{3}$ de material, correspondente a cinco toneladas cada carga, sendo que o transporte ocorre uma vez por semana (aproximadamente quatro vezes por mês). Pelas estimativas e testes realizados, com a utilização do picador, pode-se carregar, em uma caçamba de $25 \mathrm{~m}^{3}$, até dez toneladas, o que acarreta uma redução aproximada de duas cargas/mês. Neste cenário, mantendo-se a produção média de 251,78 toneladas de resíduos ao ano, temse um total de 25,18 cargas/ano, o equivalente a 2,10 cargas ao mês. Como o valor de cada carga se mantém ( $R \$ 500,00)$, o custo de transporte passaria a ser $R \$ 1.050,00$. Já o custo para manter os resíduos no aterro não sofre alterações ( $R \$ 2.099,00)$, pois o valor é cobrado pelo peso e não pelas dimensões. Portanto, tem-se um custo total com destinação dos resíduos ao aterro de $\mathrm{R} \$ 3.149,00 /$ mês.

Além disso, a utilização do picador requer alguns gastos adicionais como energia elétrica e mão de obra. Cabe destacar que, assim como mencionado na metodologia, os gastos com depreciação não são considerados, visto que o equipamento já foi adquirido e a depreciação já é considerada como um gasto para a empresa. Portanto, este valor independe da alteração no processo de descarte de resíduos, pois não há acréscimos de custos em relação ao cenário atual.

No que se refere aos demais gastos, estima-se que, para picar em média 20,98 toneladas de resíduos sólidos ao mês, são necessárias 65 horas de serviço (aproximadamente 3,10 horas por tonelada). Essas horas de serviços adicionais 
requererem o consumo de energia elétrica e de mão de obra. A Tabela 2 apresenta uma descrição detalhada do incremento de custos e energia elétrica com a utilização do picador.

Tabela 2

Acréscimo no valor de energia elétrica com a utilização do picador

\begin{tabular}{lc}
\hline \multicolumn{1}{c}{ Descrição } & Quantidade \\
\hline Consumo de energia elétrica do picador por hora de funcionamento & $13 \mathrm{KW} / \mathrm{h}$ \\
Consumo por tonelada & $40,3 \mathrm{KW} / \mathrm{ton}$. \\
Consumo total (65 horas/mês) & $845 \mathrm{KW} / \mathrm{mês}$ \\
Média do valor de energia elétrica da empresa nos meses de setembro, outubro & $\mathrm{R} \$ 0,419969 \mathrm{KW} / \mathrm{h}$ \\
e novembro de 2015, incluída a bandeira vermelha & $\mathrm{R} \$ 354,87$ \\
\hline Acréscimo na fatura de energia elétrica mensal referente ao uso do picador & \\
\hline
\end{tabular}

Nota. Fonte: Elaborada pelos autores com base nos dados de pesquisa.

Salienta-se que são utilizados, para o cálculo médio do valor de energia elétrica, os meses de setembro, outubro e novembro de 2015. A opção por esses meses devese à variabilidade das tarifas de energia, pois, assim, capta-se o efeito dos valores mais recentes do período em análise, com exceção de dezembro de 2015, que foi desconsiderado em função da ocorrência de férias coletivas da empresa, o que o torna um mês atípico.

Para o funcionamento do picador, também é necessária a utilização de mão de obra. Se houver a contratação de um colaborador para efetuar este serviço e, ao considerar que o mesmo realizará outras funções no tempo que excede a necessidade para picar os resíduos sólidos, apropria-se o gasto proporcional às horas trabalhadas. Caso contrário, ou seja, se esta contratação é exclusiva para este fim, considera-se o valor integral de sua remuneração como um gasto do processo de picar os resíduos. A Tabela 3 apresenta a descrição desses valores. 
Tabela 3

Acréscimo no valor mensal de mão de obra (MDO) com a utilização do picador

\begin{tabular}{lc}
\hline \multicolumn{1}{c}{ Descrição } & Valor (R\$) \\
\hline Salário & $\mathrm{R} \$ 1.000,00$ \\
Encargos & $\mathrm{R} \$ 800,00$ \\
Outras variáveis & $\mathrm{R} \$ 200,00$ \\
Gasto com MDO & $\mathrm{R} \$ 2.000,00$ \\
Total de horas mensais & $184,80 \mathrm{~h}$ \\
Gasto com MDO/hora & $\mathrm{R} \$ 10,82 / \mathrm{hora}$ \\
Gasto com MDO/ 65 horas & $\mathrm{R} \$ 703,30$ \\
\hline
\end{tabular}

Nota. Fonte: Elaborada pelos autores com base nos dados de pesquisa.

Ao considerar as diminuições e acréscimos de custos acima mencionados, que englobam energia elétrica, mão de obra e transporte, tem-se os seguintes resultados:

Tabela 4

Resumo dos gastos de destinação de resíduos com a utilização do picador

\begin{tabular}{lcc}
\hline \multicolumn{1}{c}{ Descrição } & $\begin{array}{c}\text { Valores (MDO destinada } \\
\text { apenas para este fim) }\end{array}$ & $\begin{array}{c}\text { Valores (MDO exercendo } \\
\text { outras atividades) }\end{array}$ \\
\hline Diminuição no gasto do frete mensal & $\mathrm{R} \$ 1.050,00$ & $\mathrm{R} \$ 1.050,00$ \\
Gasto adicional com energia elétrica & $(\mathrm{R} \$ 354,87)$ & $(\mathrm{R} \$ 354,87)$ \\
Gasto adicional com mão de obra & $(\mathrm{R} \$ 2.000,00)$ & $(\mathrm{R} \$ 703,30)$ \\
Saldo da atividade/mês & $(\mathrm{R} \$ 1.304,87)$ & $(\mathrm{R} \$ 8,17)$ \\
Saldo da atividade/ano & $(\mathrm{R} \$ 15.658,44)$ & $(\mathrm{R} \$ 98,04)$ \\
\hline
\end{tabular}

Nota. Fonte: Elaborada pelos autores com base nos dados de pesquisa.

Ainda há a possibilidade de a empresa optar por não contratar nenhum colaborador e remanejar o pessoal interno. Este remanejamento pode se dar em relação, por exemplo, ao operador de empilhadeira que, ao pegar as caixas na fábrica, já pode deixá-las ao lado do picador e exercer ele mesmo essa função. Também podese citar como possibilidades o pessoal com tempo ocioso. Desta forma, por mais que, posteriormente, se distribua uma parcela do custo de pessoal para esta atividade, não há acréscimos nos custos totais e, assim, tem-se os seguintes resultados: 
Tabela 5

Gastos de destinação de resíduos com a utilização do picador sem acréscimo de MDO

\begin{tabular}{lc}
\hline \multicolumn{1}{c}{ Descrição } & Valores \\
\hline Diminuição no gasto do frete mensal & $\mathrm{R} \$ 1.050,00$ \\
Gasto adicional com energia elétrica & $(\mathrm{R} \$ 354,87)$ \\
Gasto adicional com mão de obra & $(\mathrm{R} \$ 0,00)$ \\
Saldo da atividade/mês & $\mathrm{R} \$ 695,13$ \\
Saldo da atividade/ano & $\mathrm{R} \$ 8.341,56$ \\
\hline
\end{tabular}

Nota. Fonte: Elaborada pelos autores com base nos dados de pesquisa.

Diante do exposto, percebe-se que há diferentes perspectivas e resultados financeiros que dependem da forma com que a empresa adequa sua operação para introduzir a atividade de picotagem. Esses resultados e suas decorrências são apresentados no tópico a seguir.

\subsection{Discussão dos Resultados Financeiros}

No que diz respeito às informações supracitadas, percebe-se que, ao se considerar o gasto mais representativo desta operação, ou seja, o transporte dos materiais até o aterro sanitário, o cenário alternativo apresenta-se vantajoso à empresa. Isso porque há uma redução de custos de transporte de $R \$ 1.050,00$ mensais, com a redução de, aproximadamente, duas viagens por mês, em função do maior aproveitamento da carga pela diminuição do espaço ocupado.

Apesar da redução no número de cargas destinadas ao aterro sanitário e, consequentemente, dos custos de transporte, a alteração na forma de destinação de resíduos com a utilização do picador requer outros gastos adicionais. Os dados acima demonstram que, para a demanda atual de resíduos, o uso do picador representa um acréscimo no consumo de energia elétrica mensal de $845 \mathrm{KW}$, o equivalente a $\mathrm{R} \$$ 354,87 .

Já os custos referentes à mão de obra dependem da opção de alocação de pessoal para a realização dessa atividade. Caso a empresa opte por contratar um colaborador que atue em tempo integral na picotagem de resíduos sólidos, o gasto 
acrescido com mão de obra é de $R \$ 2.000,00 /$ mês. Este gasto adicional, somado ao acréscimo de energia elétrica, torna a atividade de picotagem inviável financeiramente para a empresa, mesmo com a redução de $R \$ 1.050,00$ nos custos de transportes, pois há um saldo negativo de $R \$ 1.304,87$ mensais, ou seja, a empresa tem um acréscimo proporcionalmente maior de seus custos.

Outra opção, conforme relatado acima, é a contratação de um colaborador que exerça outras atividades paralelas e que, portanto, possibilite a apropriação apenas dos custos proporcionais ao tempo dedicado à picotagem. Neste caso, também há um acréscimo de custos em relação ao que vem sendo praticado, por mais irrisório que seja este valor, pois passa a se ter um gasto com mão de obra mensal de $R \$ 703,30$, o que, ao compensar com os demais acréscimos e decréscimos decorrentes da picotagem, implica uma elevação de custos mensais de $R \$ 8,17$.

Entretanto, ainda há a possibilidade de remanejamento de outros colaboradores já contratados pela empresa para exercerem essa função e, desta forma, não há nenhum acréscimo de custos com mão de obra. Sem gastos adicionais de mão de obra e ao considerar apenas os valores de energia elétrica e de transporte, a empresa obtém uma redução dos custos mensais no total de $R \$ 695,13$, tornando a utilização do picador viável financeiramente.

Além de verificar o impacto nos custos, também é importante analisar o impacto ambiental dessa mudança, já que se busca uma integração sustentável entre aspectos econômicos, ambientais e sociais.

\subsection{Impacto Ambiental}

Assim como as empresas analisadas por Luczkievicz et al. (2015), a empresa objeto deste estudo também terceiriza a guarda dos resíduos até sua decomposição. Conforme dados repassados durante as entrevistas, em análise prévia para contratação do aterro sanitário, localizado no município de Chapecó - SC, constatou-se que o mesmo passou por um rigoroso estudo de impacto ambiental. O projeto da planta constitui as mais modernas técnicas de tratamento e disposição final dos resíduos 
sólidos, semissólidos e líquidos de classe I, II(a) e II(b). Tais características, além de cumprirem os requisitos exigidos pela PNRS, fazem desta a melhor opção para a destinação dos resíduos que não podem ser reutilizados (Brasil \& Santos, 2010). A empresa também tem aterro localizado na região sudeste de Santa Catarina e, com isso, atende clientes da região sul, sudeste, nordeste e centro-oeste do estado.

No que se refere exclusivamente à empresa em análise, atualmente destinam-se ao aterro sanitário 4,20 caçambas de resíduos ao mês, contendo, aproximadamente, 5 toneladas de resíduos sólidos cada uma, ou seja, uma média de 20,98 toneladas de resíduos. Esse total equivale a $105 \mathrm{~m}^{3} /$ mês de espaço no aterro sanitário, e 1.260 $\mathrm{m}^{3} / \mathrm{ano}$, ao se considerar que cada caçamba possui $25 \mathrm{~m}^{3}$ de resíduos.

O estudo prevê, com a utilização do picador, a redução pela metade no número de caçambas destinadas ao aterro sanitário no mês para transportar as mesmas 20,98 toneladas médias de resíduos. Essa diferença diminui pela metade o espaço ocupado no aterro sanitário, visto que ter-se-ia um total de $52,5 \mathrm{~m}^{3} / \mathrm{mês}$, ou seja, $630 \mathrm{~m}^{3} /$ ano $(2,10$ caçambas/mês com $25 \mathrm{~m}^{3}$ cada). Com esta redução, a capacidade do aterro sanitário pode ser duplicada, caso tivesse um espaço apenas para os resíduos da empresa citada.

Esses indicativos demonstram que, além da possível redução de custos, a mudança nos procedimentos de descarte dos resíduos sólidos da empresa também pode representar um impacto ambiental positivo. Isso porque a diminuição da área ocupada pelos resíduos da empresa no aterro sanitário potencializa sua utilização e posterga a necessidade de outras áreas destinadas a esse fim. Além disso, conforme informações repassadas pelos responsáveis do local, quanto maior a superfície de contato dos resíduos com os micro-organismos decompositores, mais rápido é a sua decomposição. Ao considerar que os resíduos gerados pela indústria analisada são $90 \%$ da classe II(a), que é da família do papelão e que levam, em média, de 3 a 6 meses para se decomporem, estima-se que esse tempo se reduza pela metade com o processo de picotagem, o que potencializa ainda mais a vida útil do aterro sanitário. 
Dessa forma, pode-se perceber que tanto o espaço ocupado quanto o tempo de decomposição dos materiais são otimizados em função da picotagem dos resíduos sólidos. Portanto, essa prática pode ser considerada uma ação "ecologicamente amigável", haja vista que, além dos benefícios ambientais descritos, a maior parte dos resíduos não possui potencial altamente poluidor e a empresa demonstra preocupação em destinar os materiais para um aterro sanitário legalizado e controlado, cumprindo as exigências legais para esse tipo de atividade. Cabe destacar que a opção pelo aterro sanitário e o controle de suas atividades também podem ser consideradas práticas ambientalmente corretas, pois, conforme destacado por Luczkievicz et al. (2015), os aterros sanitários possuem formas de impermeabilização que eliminam ou, ao menos, mitigam a contaminação do solo, dos corpos hídricos e do ar, além do surgimento de vetores causadores de doenças infecciosas.

Por fim, pode-se verificar que essa prática, além de ser viável ecologicamente, também pode apresentar viabilidade financeira, o que contraria o argumento de Rogers e Tibben-Lembke (1999), ao demonstrar que nem sempre práticas socioambientais representam acréscimos de custos, pois depende das particularidades de cada empresa e de cada situação. Em função disso, há a necessidade de se conhecer e controlar esses custos, a fim de propiciar uma gestão eficiente que potencialize seu uso e remeta a melhores resultados para a organização (lakovou et al., 2014).

\section{CONCLUSÕES}

Este estudo analisou a viabilidade, com base nos custos de tratamento e na análise de efeitos ambientais, da utilização de um picador que reduz a cubagem de resíduos sólidos antes da destinação ao aterro sanitário, em uma empresa do ramo metal-mecânico localizada na região do Alto Vale do Itajaí, em Santa Catarina.

Os achados revelam que a empresa já introduz práticas socioambientais por meio do aproveitamento máximo da matéria-prima, o que reduz seu consumo e diminui a geração e destinação de rejeitos (sobras). Esta prática de aproveitamento dos 
materiais, além de diminuir os custos com a compra de novas matérias-primas, não requer gastos adicionais, visto que o material é reaproveitado sem nenhum tratamento específico. Além do mais, contribui para a redução no espaço físico ocupado nos aterros sanitários, o que vai ao encontro às perspectivas de Silva e Cervieri (2015) e Brollo e Silva (2001), que alegam que a diminuição sistemática da produção dos resíduos na fonte, através da minimização do consumo e do desperdício de materiais e energia, torna-se uma das principais ações com vistas à redução do impacto sobre o ambiente.

Os resíduos que não são aproveitados e reintroduzidos no processo produtivo são destinados a um aterro sanitário na cidade de Chapecó - SC, o qual adequa-se aos princípios, necessidades e políticas exigidas pelos órgãos reguladores e previstas na PNRS. Para analisar a viabilidade financeira da utilização de um picador, que foi adquirido pela empresa ainda em 2011, verificaram-se os custos de destinação (armazenagem, manuseio e transporte) de resíduos que são impactados pela mudança nos processos. Pode-se constatar que, no caso de haver mão de obra adicional, o uso do picador não é vantajoso financeiramente, porém, caso ocorra a alocação de pessoal interno para a realização desse serviço, com aproveitamento do tempo ocioso de diferentes colaboradores, por não haver variação de custo com mão de obra, há uma economia de, aproximadamente, $\mathrm{R} \$ 8.341,56$ ao ano.

Também se pode verificar que a alteração do processo de destinação de resíduos com a picotagem implica a redução de impactos ambientais, mediante a maximização do tempo de vida do aterro sanitário, visto que há uma redução na área ocupada (de 100 para $50 \mathrm{~m}^{3} / \mathrm{mês}$ ) e no tempo de decomposição dos materiais. Esse fato pode trazer uma vantagem estratégica à empresa, já que esta tem pretensões futuras de receber, além do selo da ISO 9001, o selo da ISO 14000 e a introdução de práticas como estas podem auxiliar nesse processo.

Dessa forma, o presente estudo contribui ao apresentar-se como um indicativo de viabilidade financeira na introdução de práticas socioambientais, aliando maiores retornos financeiros a ações ambientalmente corretas, o que contrapõe os argumentos 
de Rogers e Tibben-Lembke (1999). Diante dessa diversificação, ressalta-se a necessidade de se considerar as particularidades da empresa e de suas operações, a fim de compreender os reais efeitos de cada ação tomada. Destaca-se ainda que este estudo considera apenas as alterações na estrutura de custos e, portanto, não analisa gastos como a depreciação do maquinário e a mão de obra já contratada, pois, mesmo que haja uma alocação desses gastos para a atividade de picotagem, os custos totais permanecem inalterados.

Todavia, o conhecimento gerado por esse estudo, além de ser útil de forma prática à empresa ao dar aporte para a tomada de decisão, também serve como incentivo a outras organizações, ao demonstrar a importância de se conhecer os possíveis efeitos de suas ações, não apenas sob a ótica financeira e econômica, mas também com vistas a contribuir com a sociedade e o meio ambiente e favorecer, assim, a sua imagem junto ao mercado. A pesquisa também é útil ao meio acadêmico, pois as evidências empíricas encontradas sustentam a necessidade de pesquisas que visem compreender os efeitos de práticas socioambientais em diferentes contextos e para outras opções de adequação.

\section{REFERÊNCIAS}

Associação Brasileira de Normas Técnicas (2004). NBR 10.004: Resíduos sólidos Classificação. Rio de Janeiro: ABNT.

Brasil, A. M., \& Santos, F. (2010). Dicionário: o ser humano e o meio ambiente de A a Z. São Paulo, Brasil Sustentabilidade.

Lei n. 12.305, de 02 de agosto de 2010 (2010). Institui a Política Nacional de Resíduos Sólidos; altera a Lei $n^{\circ}$ 9.605, de 12 de fevereiro de 1998; e dá outras providências. Brasília. 2010. Recuperado em 24 outubro, 2016, de <http://www.planalto.gov.br/ccivil/Leis/L9984.htm>.

Ministério do Meio Ambiente (2016a). Resíduos Sólidos: Contexto e Principais Aspectos. Recuperado em 25 dezembro, 2016, de $<$ http://www.mma.gov.br/cidades-sustentaveis/residuos-solidos/politica-nacional-deresiduos-solidos/contextos-e-principais-aspectos $>$. 
Ministério do Meio Ambiente (2016b). Resíduos Sólidos. Recuperado em 21 setembro, 2016, de <http://www.mma.gov.br/cidades-sustentaveis/residuos-solidos>.

Brollo, M. J., \& Silva, M. M. (2001). Política e gestão ambiental em resíduos sólidos. Revisão e análise sobre a atual situação no Brasil. Anais do $21^{\circ}$ Congresso Brasileiro de Engenharia Sanitária e Ambiental. João Pessoa, Paraíba.

Compromisso Empresarial para Reciclagem - Cempre (2016). Reciclagem de Lixo: O que é lixo classe 1. Recuperado em 08 agosto, 2016, de <http://www.meioambientenews.com.br/conteudo.ler.php?q\%5B1\%7Cconteudo.idca tegoria\%5D=31\&id=6553>.

Souza, S. F. de, \& Fonseca, S. U. L. da (2009). Logística reversa: oportunidades para redução de custos em decorrência da evolução do fator ecológico. Revista Terceiro Setor \& Gestão-UNG-Ser, 3(1), 29-39.

Ciliberti, F., Pontrandolfo, P., \& Scozzi, B. (2008). Logistics social responsibility: Standard adoption and practices in Italian companies. International Journal of Production Economics, 113(1), 88-106.

Claro, P. B. O. \& Claro, D. P. (2014). Sustentabilidade Estratégica: existe retorno no longo prazo? Revista de Administração de Empresas, 49(2), 291-306.

Daher, C. E., Silva, E. P. D. L. S., \& Fonseca, A. P. (2006). Logística reversa: oportunidade para redução de custos através do gerenciamento da cadeia integrada de valor. BBR-Brazilian Business Review, 3(1), 58-73.

Silva, F. da, \& Cervieri, L. (2015). Tratamento de Resíduos Sólidos: uma grande contribuição para o meio ambiente. Maiêutica-Gestão Ambiental, 3(1), 41-47.

Gil, A. C. Como elaborar projetos de pesquisa (2002). 4. ed. São Paulo, Atlas.

Henry, R. K., Yongsheng, Z., \& Jun, D. (2006). Municipal solid waste management challenges in developing countries-Kenyan case study. Waste management, 26(1), 92-100.

lakovou, E., Mallidis, I., Vlachos, D., \& Dekker, R. (2014). A Methodological Framework for Green Logistics Networks under Periodic Review Replenishment Policies. Anais do Conferência Anual - Royal Holloway University of London, Londres, Inglaterra, 56.

Kuzma, E. L., da Luz, T. E., Novak, M. A. L., \& Navarro, R. M. (2017). Tratamento de resíduos sólidos e efluentes: uma análise de custos em empresas de revenda de combustível. Revista Metropolitana de Sustentabilidade, 7(3), 25-46. 
Luczkievicz, C., Menegat, M. O., \& Figueiredo, A. M. B. (2015). Destinação de resíduos sólidos gerados por empresas metalúrgicas localizadas no município de ChapecóSC. Revista Tecnológica, 3(2), 284-299.

Marchese, L. de Q., Konrad, O., \& Calderan, T. B. (2011). Logística reversa e educação ambiental contribuindo para a implantação da Política Nacional de Resíduos Sólidos. Revista Caderno Pedagógico, 8(2), 83-96.

Ribeiro, R. B., \& Santos, E. L. dos. (2013). Análise das Práticas Estratégicas da Logística Verde no Gerenciamento da Cadeia de Suprimentos. Revista de Administração da UNIFATEA, 5(5), 20-40.

Rogers, D. S., \& Tibben-Lembke, R. S. (1999). Going backwards: reverse logistics trends and practices. Pittsburgh: RLEC Press.

Secretaria do Meio Ambiente do Estado de São Paulo (2014). Plano de Resíduos Sólidos do Estado de São Paulo. Recuperado em 25 novembro, 2016, de <http://www.prefeitura.sp.gov.br/\%20cidade/secretarias/upload/servicos/arquivos/P GIRS-2014.pdfemv>.

Data de Submissão: 25/05/2018

Data de Aceite: 07/05/2019 